\title{
From Unity to Harmony in Diverse World through Global Service-Learning: A Case Study from Korea
}

\author{
Sookyoung Ryu ${ }^{1, *}$ and Youngwoo $\mathrm{Kim}^{2}$ \\ ${ }^{1}$ General Education Department, 01797 Seoul Women's University, 621 Hwarang-ro, Gongneung \\ 2(i)-dong, Nowon-gu, Seoul, Korea \\ ${ }^{2}$ German Language and Literature Department, 01797 Seoul Women's University, Korea
}

\begin{abstract}
The purpose of this study is to explore the effect on the development of participant students through Global Service-Learning (GS-L) as global citizens in this diverse world. In multi-cultural and multiracial contries people has good ways to live in harmony with others different. In Korea, they live in unity with one rational background and with the only one language. The GS-L in Malaysia allowed nine Korean students to have more involved in Malaysian real lives through homestay and cultural exchange program. This cultural exchange program contributed to the better global citizenship education which is considered very important in this global village, adding another exotic nutrient to Korean substantial culture. The experiences in Malaysia enable students to find ways to solve various problems and conflicts with differences as Korea is becoming more and more multi-cultural society.
\end{abstract}

Keywords: Cultural exchange, diversity, global service-learning, harmony.

\section{Introduction}

As Service-Learning is an educational method, the Global Service-Learning (GS-L) is one credit course of Seoul Women's University (SWU), integrating academics and active learning and community-based service in an international context [1]. SWU has been conducted GS-L in international contexts since 2010 with overseas partners in Philippines, Vietnam, Cambodia, India, and Mongolia. In 2016 SWU initiated a new GS-L program with the IPG KENT Teacher Education College in Malaysia. This paper is a case study on how to build collaborative partnership for new GS-L program, and on the experiences of the participants, mainly those of students. This case should reflect on the specific situation of the social and cultural background of the participants, mainly on the situation of Korea from the perspective of students who are the active subjects of GS-L from planning to evaluation.

*Corresponding author: gracersy@,naver.com 
Because Korea was one ethnic family speaking one language, with few foreigners, the value of unity or oneness was the uniqueness of Korean people. However, with a growing number of foreigners in Korean society, Korea is no longer homogeneous country and becoming a multicultural society very quickly. It means that Korean people have to open their mind and prepare themselves as good citizens making harmony more important than unity as the best value in this open global society. In that context, international program has become a focus for higher education in Korea.

As this international program requires the participant students to pay a big amount costs, SWU has to provide them with financial supports in order to encourage more to participate in it. That means that SWU is willing to cover more than half of the costs because they think GS-L has a big possibility to achieve the educational purpose of SWU. GS-L or international experiential programs allow participants to open their minds to different cultures and to develop intercultural competence and global civic awareness [2-5]. According to the findings from those case studies and the main objectives of GS-L, the research questions are as followings:

i. How have students reported serving the world community in remote area, and sharing with them the global issues in environment, campaigning public health as well as understanding cultural diversity etc.

ii. How were students' capacity developed to be honorable global citizens after playing key roles for conducting the program, along with local members.

iii. How were students' perspective widen on purpose of contributing for local community.

Data came from responses on the students journals and minutes on reflection meetings after every activities.

Through GS-L SWU has been building up good partnership with Asian countries including Cambodia, China, India, Mongolia, Philippines, Vietnams based on cooperation with the local universities, schools, NGO's and community members. Instead of the existing GS-L teams consisted of various academic backgrounds from the different five colleges of SWU, GS-L Malaysia team consisted of students who are taking some particular classes, Korean Traditional Culture and Clothing majoring classes. This study is mainly focused on the group majoring Korean Clothing that had successfully performed GS-L in Sabah, Malaysia on January of 2017. GS-L, working with populations from different cultures will influences on students' cultural sensitivity [6]. This paper will show the process of building partnership, from planning to implementation and evaluation GS-L program, and also the effects of GS-L on development of students, especially on their cultural sensitivity and acceptability.

\section{Global service-learning in Malaysia}

\subsection{Planning of GS-L}

As the objectives of this GS-L team consisting of students majoring Korean clothing and culture, after this program, they will be able to:

i. Perform the global projects with collaboration with others from different countries and various cultures,

ii. Introduce the Korean culture effectively and fascinatingly, particularly with traditional costumes, to foreigners,

iii. Understand the Sabah costume and craft related to Malaysian culture,

iv. Establish the continuous friendship between sides, through continuous GS-L program, 
v. Develop the appropriate program for mutual interests.

As a kind of talent donation, students developed Korean Traditional Costume Experience Program and prepared teaching materials based on what they have learned at the 'Han-Bok, Korean Traditional Costume Design' class or 'Korean Clothes and Culture' class. During the design class, students majoring clothing science made their Han-Boks by themselves. As Han-Bok is made of silk designed uniquely with beautiful lines and various colors, foreigners really enjoyed trying Han-Bok for experience and for taking photos. Students wanted to introduce Korean traditional and modern culture as well as costume, and of course loved to learn Malaysian ones. Through exchange of each other's culture both Malaysian and Korean students may gain new base and insights to proceed over the limit as pioneers forward the new era. Especially Korea is surrounded by seas that keep Korea isolated from outer worlds and blocked by North Korea after divided over more than 60 years, and travelling overseas was restricted until late 1980's. The Sense of Community is still much stronger than individualism in Korea, they have developed very unique culture and one language. It is why GS-L in Malaysia will contribute to widen the viewpoints of Korean students and promote their cultural receptivity

\subsubsection{Class based GS-L}

This class based GS-L is the first thing that GS-L Malaysia differs from other exsisting GSL programs. While $<$ Han-Bok Design $>$ is a majoring course of clothing science, $<$ Korean Clothes and Culture $>$ is the liberal arts class for all students. In $<$ Han-Bok Design $>$ practice class, students actually designed and made their own Korean Traditional dress. The $<$ Korean Clothes and Culture $>$ is a theory class dealing with traditional clothes through Korean history and culture. GS-L Malaysia team is composed of volunteer students from these two classes; wonderful combination, some from practice class and the others from theory class on Korean costumes. Also, it was a suitable team to teach Korean culture.

\subsubsection{Team members}

The GS-L team consisted of total nine students; six ones majoring clothing science and other three ones majoring Chinese language, German language, and computer science each. The six students took the $<$ Han-Bok Design $>$ major class while the other three did the $<$ Korean Clothes and Culture $>$ class. Their various backgrounds were useful not only for introducing Korean things but also for understanding foreign things and dealing with media.

\subsubsection{Contact local partners}

For GS-L in winter vacation, we started developing the programs and looking for local partners in second semester of 2016. It is true that the personal network of the professor in charge of the S-L classes initiates official collaboration and partnership between SWU and KENT College in Malaysia for GS-L program according to the principle of reciprocity. As the Service-Learning during the semester, Korean Costume Experience Program was developed until November and implemented for the foreign students on the days of academic seminar.

\subsubsection{Program in brief}

At the Pre-meeting with partner Malaysian school, Korean students did: 
i. adjust the time allocation for the each program and confirm the main concept,

ii. identify the program site and confirm the allocation of host family for the student,

iii. greet program teachers in charge from both sides,

iv. detail preparation for the activities,

v. exchange the student information/host details, and

vi. finalize the participants/grouping depending upon the activities.

Table 1. An example of program plan

\begin{tabular}{|c|c|c|c|c|}
\hline & \multicolumn{3}{|c|}{ Program 3} & Materials \\
\hline Program name & Korean traditional game & Capacity & 20 & \multirow{4}{*}{$\begin{array}{l}\text { ppt about traditional } \\
\text { games of Korea/visual } \\
\text { materials of } \\
\text { traditional play of } \\
\text { Korea/Yut } \\
\text { sets/Newspapers for } \\
\text { TTak-ji }\end{array}$} \\
\hline \multicolumn{4}{|c|}{ Activity Content } & \\
\hline Summary & \multicolumn{3}{|c|}{ Try traditional games of Korea (Game of Yut, TTak-ji) } & \\
\hline \multicolumn{4}{|c|}{$\begin{array}{l}\text { Learn traditional games of Korea by visual materials } \\
\text { Fold a ttakji toghether } \\
\text { - Game of Yut/ttakji with traditional games of Korea } \\
\text { - try traditional games of Malaysia }\end{array}$} & \\
\hline
\end{tabular}

\subsection{Implementation of GS-L}

\subsubsection{Prior activities}

The prior preparation education included cultural competency training, communication and coordination with community, and comprehensive assessment and strategic planning for SL activities [7]. This course facilitate the students to reflect on their conceptions of self [8]. This self-exploration included reflecting on the culture and knowledge on their own country, Korea.

Table 2. Process of prior preparation activities.

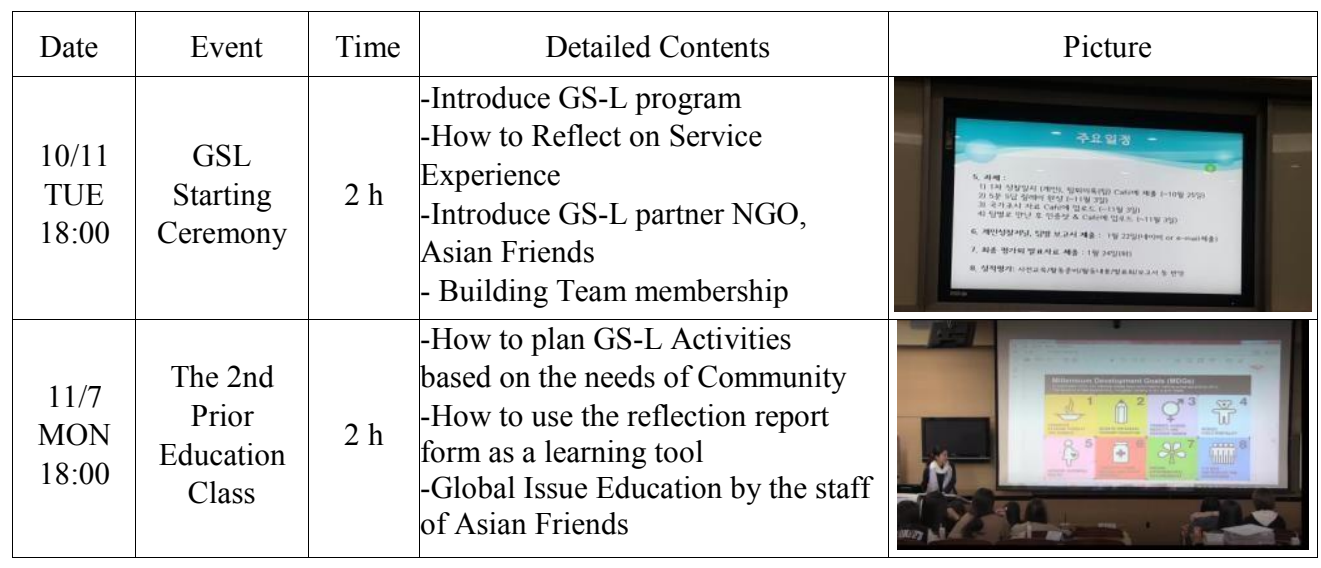

Table 2. continue to the next page 


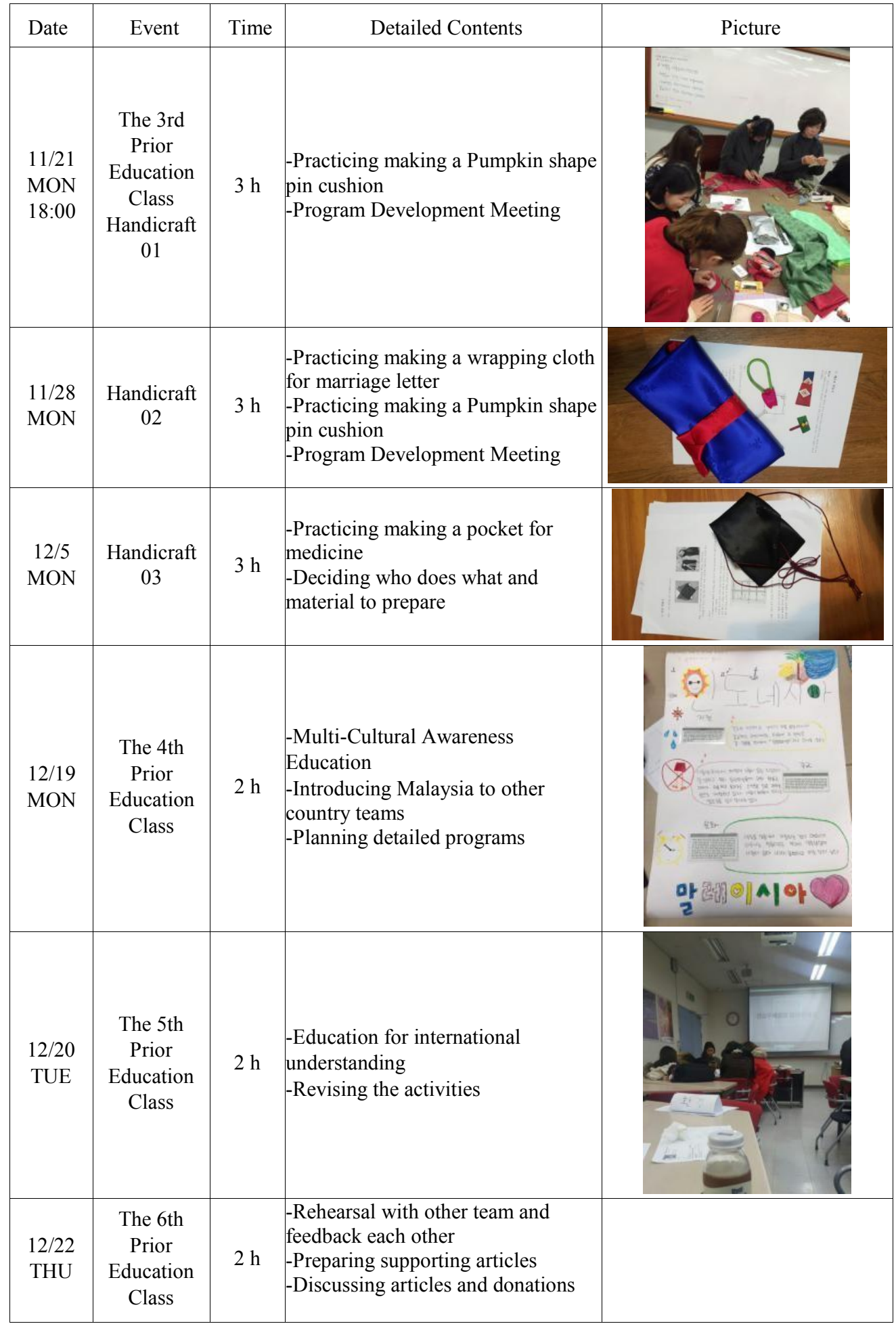

Table 2. continue to the next page 
Table 2. Process of prior preparation activities (Continued).

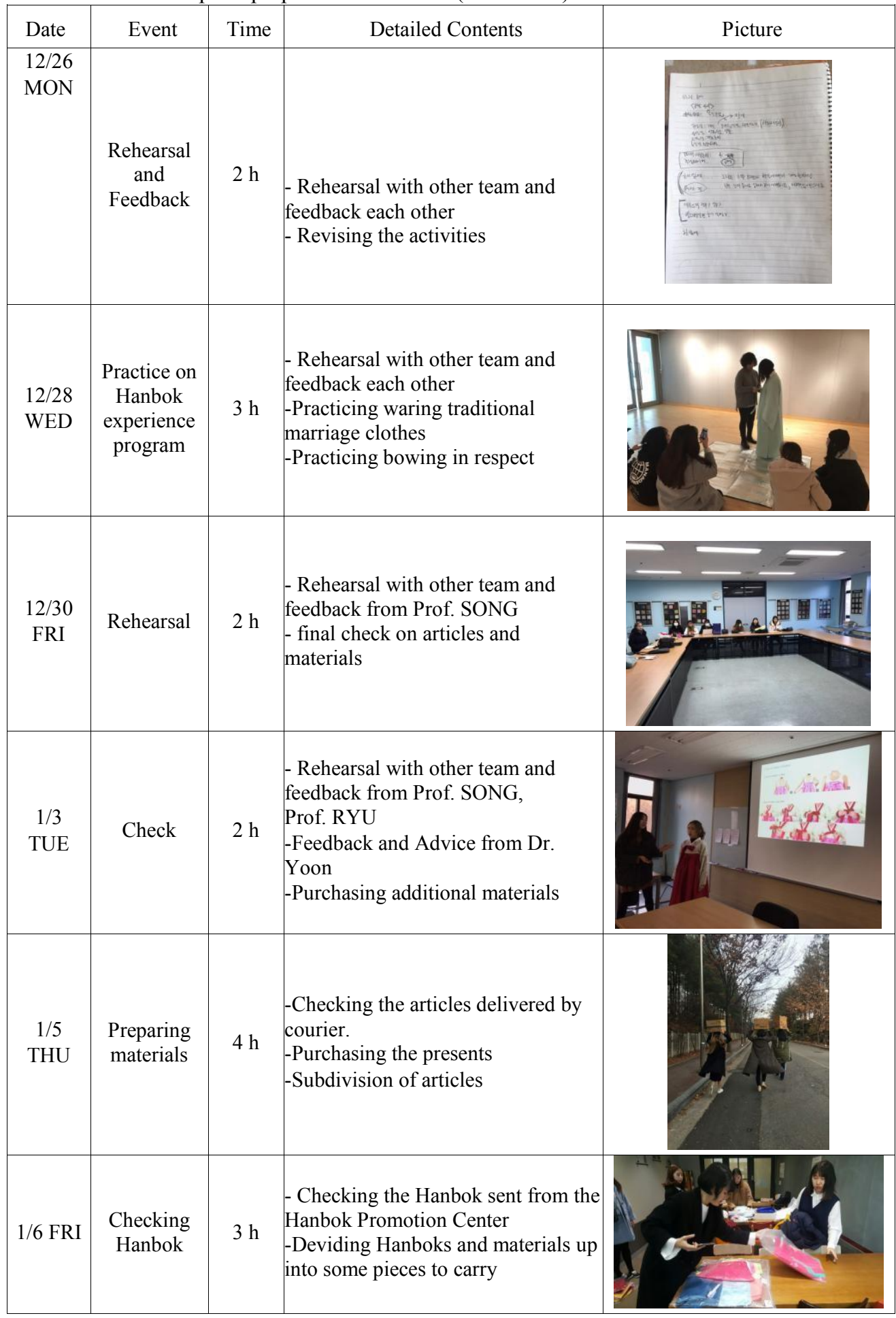




\subsubsection{Visiting Places}

GS-L was two week program. In the first week they home stayed at the first community, site A. GS-L team divided into two or three members to live with teachers' families each. The school community is really like one family and teachers know all the students very well and are chummy with them. Because their houses are scattered at a distance, it seems not easy for them to meet and communicate after school. The host family of school A provided our students and the professor with comfortable accommodation, transportation, meals covering whole stay with them. The school A provided them with breakfast on week day before the morning program.

At the second community, site B in the next week, students needed more time and physical energy than expected to adapt themselves to the new environment and culture. They asked the community partners to allow them to stay at dormitory of school instead of homestay with local families at the village in a forest. The school B supplied also restful accommodation, transportation, heartfelt prepared meal during their stay at the school dormitory.

\subsubsection{Activities}

The main activities of GS-L are exchange cultures with middle school students, homestay with host family, and reflection sharing meetings. Because of hot weather SWU students was exhausted after the activities and visiting sites after school. Some suggested that the period of GS-L may be shortened from two weeks to about $10 \mathrm{~d}$ or the number of sites could be only one. It can be considered that Malaysian university students will join GS-L with SWU students from the planning. The daily reflection meeting after the activities should not be missed, for reflection on the effects of that day's activities and also for preparation for next day's ones. These were good way for them to deepen their gratitude for helpers and local teachers and other students through representation of their heart in words, and then some conflicts could be settled.

\subsubsection{Collaboration with Malaysian local partners}

The supports and hospitality from IPG KENT for SWU GS-L program was more than expectations. From the planning to evaluation of this program, the coordinators have helped the GS-L team with good guides, tips, and advices to understand. The students stayed at homes of some teachers in two or three persons each. They enjoyed living together with foreign families and being accepted as a family member with gratitude. Most of them keep in touch with the families and communicate through WhatsApp and Facebook. It was reported that they gained life-long friends through only one week homestay. The emotional responses are very important part of learning in international S-L [9].

\subsubsection{Learning from reflection and feedback}

With the meeting for reflection and feedback GS-L may be differentiated from other international service programs. The all students wrapped the program of the day up together with the professors of SWU and Kent Campus, Malaysian partner university, and sometimes with the local teachers. While SWU students hosted the meeting turn by turn, students tried to find the meaning of that day's experience, solve any conflicts through communication. It was a good opportunity for them to realize that the experiences are changed into new and meaningful knowledge through representation with words with colearners. They could feel and think from others' places and build a collaborative 
teamwork among them. What they had talked and discussed were all recorded and documented.

\section{Results of GS-L program}

\subsection{Learning how to serve the world through collaboration with others}

For many students this was the first experience to live with foreigners and to be accepted as a member of their community. Though they will soon graduate and go into the real world, they have yet little opportunity to face the real problems to solve with their knowledge. They have no experience to make relationship with foreigners or people from different culture. And the real world is so dynamic and always over their expectation and preparation. They should read the situation quickly and have little time to make the best decision but have to take any action to solve the problem or to complete their missions. For example, they have to change the four day program to three day with skipping some of the planned activities. Instead they were asked to join their sports day program as supporters. The number of students was extremely bigger than their expectation. They had asked and expected just only 20 students would join, but more than hundreds students were gathered to join the Trying Han-bok on program. They could perform the program successfully with the support of teachers who understood what they planned to do. With such experience they will be prepared to handle real world problems through collaboration with partners.

"I will surely not forget you. Thank you so much, for you are my real family in Malaysia who help me to huddle the tasks that seem impossible and to have self-confidence." (D.B. Kim)

\subsection{Learning how to be good global citizens through Understanding each other}

\subsubsection{Differences: languages, religiions, culture, living styles, ets.}

The Korean students felt the biggest difference between Malaysia and Korea may be whether it has the established religion or not. Though Islam is the state religion in Malaysia, Korea does not have any official one. However, the two countries guaranteed freedom of religion. In Malaysia, some people believe in Buddhism, Hindu, and Roman Catholic and Protestant Christianity. The religion is most important and has a powerful influence on their lives, which SWU students all feel in their clothes, foods, time to pray in their schedule, and talking with them. According to their religion's requests, the Malaysian women always cover their hair with hijab in such a hot weather. Meanwhile there are more than half of the population who has no religion in Korea, and two thirds of GS-L students said they believed in themselves instead of any traditional religion. For Malaysian people it sounded strange that many Korean have no religion. For Korean students it looked wonderful that the all Muslim family members get up early to pray together at 5 am every morning and that they finish their school day earlier on Friday for weekly pray ceremony at the temple.

"With my newly widened view on the world I expect to be able to share my knowledge and love with others, and continuously try to serve them. I will keep in touch my Malaysian friends to understand their culture better and help them to understand ours." (S. J. Han) 


\subsubsection{Similarity: human nature, the value of Kindness and open-mind}

They felt social atmosphere in Malaysia was very similar to that in Korea, modernized and open minded. Most Korean people has few opportunity to meet Muslim people and what they can hear regarding Islam is mostly about terrorism from the world news. They think Muslim women are discriminated against because they have to hide their body and hair. So they think Muslim people may be conservative. But they look many active Malaysian Muslim women working as teachers and professors, having voices, and leading the society together with their male coworkers. Muslim men were not terrifying but so kind and openminded, that they accepted unbiasedly Korean students, who are foreigners, having different religion or no religion.

'I stayed with Muslim family whom we rarely see in Korea. Though it was my first experience to live with foreigners, I felt comfortable and thought we are really all alike.' (J. H. Jeon)

\subsection{Learning how to be open with the coming multi-cultural society}

Korea has been uni-cultural society as a single-race nation with one language since it was founded. It was totally new challenge for Korea to open to the multi-cultural world with now rapidly becoming a multi-cultural society. As the number of foreigners in Korea is on the rise and also expected to increase continually in future (Fig. 1.), they say Korea should learn the multi-cultural world and tolerance to difference and prepare its coming. This is why Global Service-Learning in Malaysia is useful and having educational values.

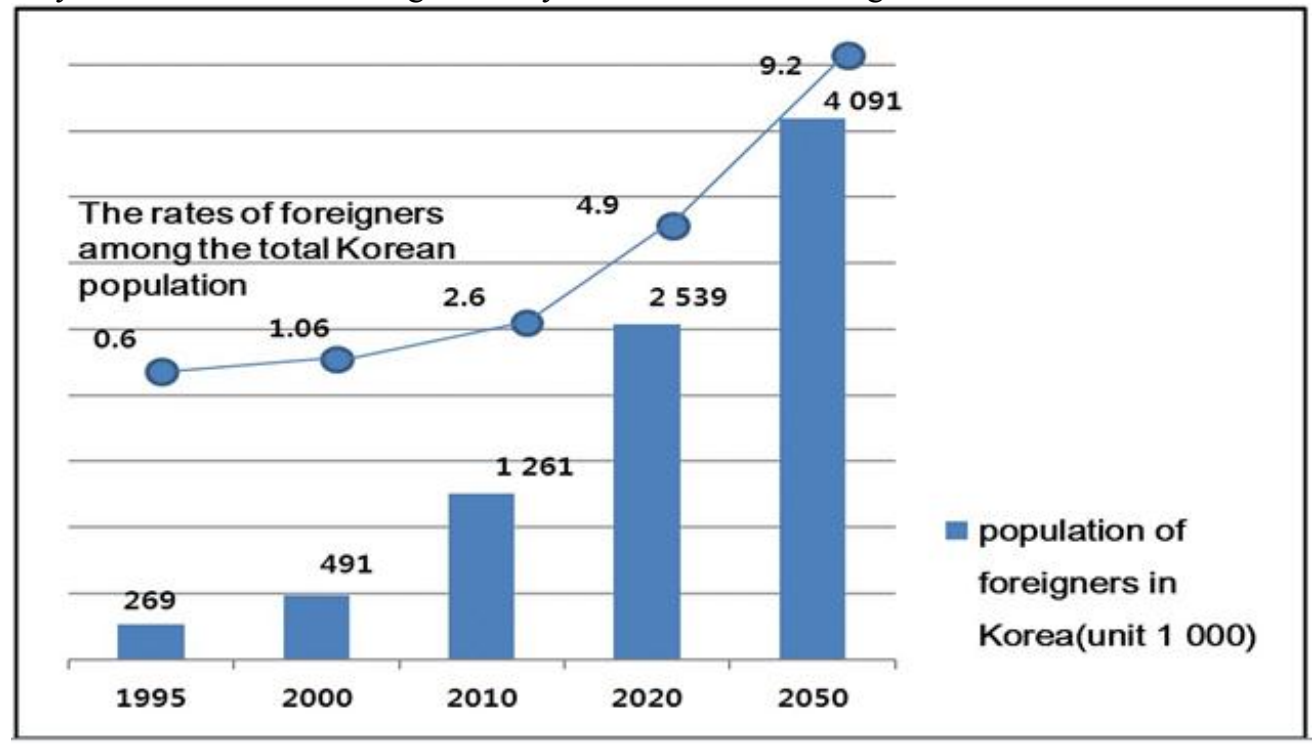

Fig. 1. The rates and numbers of foreigners in Korea [10].

'Based on what I have learned through GS-L, I will keep trying to learn other cultures and languages more, and to be more concerned with the Global issues including environment and children in our society. '(J. H. LEE) 


\section{Conclusion}

The collaboration, understanding, and partnership are the keys for the success of GS-L program. With unstinting support and open minded acceptance of IPG KENT, the partnership has been well built between IPG KENT and SWU though this is the first visit to Malaysia. Especially it was the first GS-L program designed on the class objectives, while the existing GS-L programs of SWU were just on the student individual interests and community needs. After GS-L students can be able to perform the global projects with collaboration with others from different countries and various cultures. They can introduce the Korean culture effectively and fascinatingly, particularly with traditional costumes, to foreigners. Malaysian people are not foreigners but like family for them now, communicating with them through WhatsApp and Facebook building friendship continually. They will be also able to develop appropriate programs respecting mutual interests, for they have learned the beauty and value of harmony with various colors rather than unity with one color in Malaysia and Malaysian friends. And they are expected to contribute Korean society will open its mind to multi-cultured world in future.

\section{References}

1. R.D. Crabtree. Michigan Journal of Community Service Learning, 15,1:18-36(2008). https://eric.ed.gov/?id=EJ831380

2. L.E. Metcalf. Journal of Marketing Education, 32,2:155-171(2010). http://journals.sagepub.com/doi/pdf/ 10.1177/0273475309360157

3. S.Y. Nickols, N.J. Rothenberg, L. Moshi, M. Tetloff. Journal of Higher Education Outrech and Engagement, 17,4:97-124(2013). http://openjournals.libs.uga.edu /index.php/jheoe/article/view/1114/719

4. K.L. Daniel, C. Mishra. Sage Open, 7,1:1-11(2017). http://journals. sagepub. com/doi/pdf/10.1177/2158244017697155

5. C.H. Wu. Languange Teaching Research, 22,5:517-531(2017). https://journals.sagepub.com/doi/abs/10.1177/1362168817718573?journalCode=ltra

6. E.D. Jones, L.L. Ivanov, D. Wallace, L. VonCannon. Home Health Care Management \& Practice, 22,7:464-469(2010). http://journals.sagepub.com/doi/abs/10.1177/1084822310368657

7. J.B. Lattanzi, C. Pechak. CFISL., JAH., 40,2:103-109(2011). http://www.ingenta connect.com/content/asahp/jah/2011/00000040/00000002/art00010

8. M. Yang, L.Y.Y. Luk, B.J. Webster, A.W.L. Chau, C.H.K. Ma, ISL., JSIE., 20,5:416436(2016). http://journals.sagepub.com/doi/pdf/10.1177/102831 5316662976

9. M.A. Larsen. Journal of Experiential Education 40,3:279-294 (2017). https://journals.sagepub.com/doi/abs/10.1177/1053825917706379

10. National Statistical Office. Annual Census of Population. [Online] from http://kostat.go.kr/portal/korea/kor_nw/2/1/index.board?bmode=read\&aSeq $=247687$ (2011). [Accessed on 22 March 2017]. 